\title{
EVALUATION OF NEUROLOGICAL MANIFESTATIONS IN HUMAN IMMUNODEFICIENCY VIRUS-AIDS PATIENTS ADMITTED TO SOUTH INDIAN TERTIARY CARE HOSPITAL - A CROSS-SECTIONAL STUDY
}

\author{
ARUN SINGH TEJAVATH ${ }^{1}$, AMIT MATHUR ${ }^{1}$, PRATIMA SINGH ${ }^{2}$, SUPRIYA SUMAN $^{2}$, PREETI RAJ $^{2}$, \\ MURALI VENKATESHWARA $\mathrm{T}^{3}$
}

${ }^{1}$ Department of Gastroenterology, NIMS University Rajasthan, Jaipur, India. ${ }^{2}$ Department of General Medicine, NRI Medical College and General Hospital, Guntur, Andhra Pradesh, India. ${ }^{3}$ Department of Pharmacy Practice, NIMS University Rajasthan, Jaipur, India. Email: tejavathdm@gmail.com

Received: 07 July 2020, Revised and Accepted: 27 August 2020

ABSTRACT

Objective: The objective of the study was to describe, evaluate, and analyze neurological manifestation in human immunodeficiency virus HIV positive patients admitted to a tertiary care center.

Methods: The study was a prospective cross-sectional study, in which 103 HIV patients were analyzed. All patients were interviewed face to face and evaluated by the investigator with particular reference to neurological manifestations. They were classified into various stages of HIV using the World Health Organization staging system.

Results: The mean age in males was 37 (standard deviation [SD] 8.0) years and in females 35 (SD 7.0) years. A greater proportion of females were diagnosed in the asymptomatic state during screening, either during pregnancy or when the spouse was found to be positive. Headache was the most common neurologic symptom and fundus abnormalities were the most common neurological sign documented in patients. The mean CD4 counts in males are $156.5 / \mathrm{mm}^{3}$ and in females are $229.57 / \mathrm{mm}^{3}$ whereas the mean absolute leukocyte count in males is $1088.30 / \mathrm{mm}^{3}$ and in females is $1473.52 / \mathrm{mm}^{3}$. The CD4 counts showed a better correlation with the occurrence of neurological manifestations than absolute leukocyte count.

Conclusion: Headache was a significant predictor of the occurrence of neurological complications ( $\mathrm{p}=0.01)$. CD4 counts were significantly lower in patients with neurological complications and most of the neurological manifestations; on the contrary, all the opportunistic infections were documented in patients with CD4 counts below 200/ $\mathrm{mm}^{3}$. Neurological complications did not show any correlation with the patient being on antiretroviral therapy.

Keywords: Cryptococcal meningitis, Human immunodeficiency virus/AIDS, Neuro-infections, Toxoplasmosis, Tuberculosis.

(C) 2020 The Authors. Published by Innovare Academic Sciences Pvt Ltd. This is an open access article under the CC BY license (http://creativecommons. org/licenses/by/4. 0/) DOI: http://dx.doi.org/10.22159/ajpcr.2020.v13i11.38968

\section{INTRODUCTION}

India is mainland to the third population of people living with human immunodeficiency virus (HIV) and AIDS [1]. With the first case detected in 1986 among female sex workers, today India reports more than 5.134 million infections [2,3]. HIV belongs to the class of lentiviruses genus (Retroviridae family), characterized by immunodeficiency, neoplasia, and neurologic manifestations. HIV is a neurotrophic and neurovirulent syndrome which is classified under primary neurologic disease and secondary (opportunistic infection [OI]). The presumed mechanism of central nervous system (CNS) invasion states under the term "Trojan horse," in which monocytes are admitted into the blood-brain barrier followed by an aggressive immune response in the recrudescence of the disease [4]. Shorter survival of AIDS is strongly associated with late diagnosis and development of CNS-related OI [5].

With a multidisciplinary approach under the umbrella of the National AIDS Control Organization (NACO), India has made great progress to control the spread of the infection. Still due to socio- diverse culture with limited resource antiretroviral is unaffordable to a larger section of society [6]. This had resulted in the rise of neurological manifestation cases in HIV/AIDS. In spite of wide prevalence, there is a scare in neuroepidemiology studies on HIV patients from the southern part of the Indian sub-continent. The objectives of the study were to evaluate the prevalence of neurological manifestation in HIV positive patients admitted to a tertiary care center and also to find the possible predictors of neurological manifestations.

\section{METHODS}

\section{Setting}

This is a prospective observational study carried out between October 2017 and June 2019 on 103 consecutive HIV patients in different stages of disease seen as inpatients in NRI Medical College and General Hospital, Chinakakani, Guntur, Andhra Pradesh. All respondents were adults, aged $>18$ years who gave informed consent were included in the study.

\section{Patients}

Patients were selected on an in-patient basis. The in-patients were those who were admitted to the medical wards of NRI Medical College and General Hospital, Chinakakani, during the aforementioned period with a diagnosis of HIV infection. The first consecutive 103 patients admitted and who were willing to participate in the study were included in the study.

All patients were interviewed and examined by the investigator. Emphasis was particularly laid on identifying the stage of the disease and also on recognizing neurological manifestations of HIV. Investigations were done based on the needs of the patients after a thorough clinical evaluation.

Tests

HIV was confirmed by the ELISA test. Total count and differential count were performed in the laboratory using automated counting 
chambers and confirmed manually.CD4 counts were analyzed using the flow cytometry method. Other tests were done as per the needs of the patient.

Patients with a diagnosis of neuro-AIDS were treated according to the NACO guidelines using anti-retroviral treatment (ART), antitubercular, antifungal, decongestants, antibiotics, and anticonvulsants medications. Associated OI were treated with respective drugs.

\section{Sample size}

All 103 patients who presented to the hospital during the study period were chosen.

\section{Statistical analysis}

Data analysis was performed using SPSS for Windows version 13.0. Mean and median were used as measures of central tendency and standard deviation (SD) were used as a measure of dispersion for descriptive statistics. Chi-square and Pearson's test has been used to test the association between CD4 counts and absolute lymphocyte count (ALC) counts and their association with neurological manifestations and duration of HIV.

\section{RESULTS}

\section{Demographic distribution and HIV classification}

In Table 1, of 103 patients, $78.6 \%$ were male and $21.4 \%$ were female. The mean age in males was $37 \pm 8.0$ and females was $35 \pm 7.0$ consecutive years. Seventy-three patients were married whereas $41(39.8 \%)$ of participants had 0-10 months duration of HIV history.

A greater proportion of females were in the asymptomatic state during screening, either during pregnancy or when their spouse found positive. Patients were classified under HIV using stage criteria. Nineteen $(18.4 \%)$ were in Stage 1, 14 (13.6) were in Stage 2, 23 (22.3\%) were in Stage 3, and 47 (45.6\%) were in Stage 4, respectively.

\section{Neurological investigation}

Cerebral spinal fluid (CSF) examination was diagnosed in 35 of the 40 $(87.5 \%)$ of patients who underwent the study.

The computed tomography/magnetic resonance imaging findings were cerebral edema in $18 \%$, cerebral atrophy in $10 \%$, space-occupying lesions brain in $10 \%$, periventricular infarcts in $10 \%$, and other infarcts in $7 \%$. In $45 \%$ the imaging studies were normal. The space-occupying lesions detected include toxoplasmosis (2), CNS Lymphoma (1), and tuberculoma in a patient with Disseminated tuberculosis (1) (Table 2)

Out of the six patients who had symptoms suggestive of peripheral neuropathy, three patients had an abnormality detected on the ENMG. Small fiber neuropathy may be associated with a normal electroencephalogram (EEG).

EEG was done in five patients and all of them were normal. Sural nerve biopsy was done in two patients showed sensory axonal neuropathy. Brain biopsy finding in one patient showed CNS lymphoma.

\section{Neurological signs and symptoms}

Headache was the most common symptom seen in 39 patients and was associated with vomiting in 31 patients. This was followed by seizures and altered sensorium. Gait abnormalities (12\%) included spastic $(4 \%)$, ataxic $(4 \%)$, and paralytic $(4 \%)$. These were the most common neurological signs at presentation. The etiological diagnoses in these patients included tuberculous meningitis (TBM) and Cryptococcal meningitis (3), TBM (3), and CNS Lymphoma (1). Monoplegia documented in three patients was due to TBM (Fig. 1).

\section{Disease spectrum}

In Table 3, of the 103 patients 41 had neurological complications subdivided into TBM $(13.6 \%)$ was the most common neurological manifestation seen, followed by cryptococcal meningitis (10.7\%),
Table 1: Demographic distribution of the study population $(n=103)$

\begin{tabular}{|c|c|c|}
\hline Characteristics & $\mathbf{n}$ & $\%$ \\
\hline \multicolumn{3}{|l|}{ Sex } \\
\hline Male & 81 & 78.6 \\
\hline Female & 22 & 21.4 \\
\hline \multicolumn{3}{|l|}{ Age } \\
\hline 20-30 years & 22 & 21.4 \\
\hline $31-40$ years & 54 & 52.4 \\
\hline $41-50$ years & 19 & 18.4 \\
\hline$>50$ years & 8 & 7.8 \\
\hline \multicolumn{3}{|l|}{ Marital status } \\
\hline Single & 14 & 13.6 \\
\hline Married & 73 & 70.9 \\
\hline Widowed & 16 & 15.5 \\
\hline \multicolumn{3}{|l|}{ Duration of HIV } \\
\hline $0-10$ months & 41 & 39.8 \\
\hline 11-20 months & 26 & 25.2 \\
\hline 21-30 months & 9 & 8.73 \\
\hline 31-40 months & 7 & 6.8 \\
\hline 41-50 months & 8 & 7.8 \\
\hline 51-60 months & 7 & 6.8 \\
\hline$>61$ months & 5 & 4.5 \\
\hline \multicolumn{3}{|l|}{ Mode of diagnosis } \\
\hline OI & 62 & 60.2 \\
\hline Spouse positive & 21 & 20.4 \\
\hline Routine & 18 & 17.5 \\
\hline Intercurrent illness & 2 & 1.9 \\
\hline \multicolumn{3}{|l|}{ Substance abuse } \\
\hline Alcohol & 62 & 60.2 \\
\hline Smoking & 65 & 63.1 \\
\hline \multicolumn{3}{|l|}{ HIV staging } \\
\hline 1 stage & 19 & 18.4 \\
\hline 2 stage & 14 & 13.6 \\
\hline 3 stage & 23 & 22.3 \\
\hline 4 stage & 47 & 45.6 \\
\hline \multicolumn{3}{|l|}{ Residential area } \\
\hline Hyderabad & 1 & 0.9 \\
\hline Bengaluru & 32 & 31.2 \\
\hline Karnataka outside Bengaluru & 36 & 5.0 \\
\hline Andhra Pradesh & 20 & 19.5 \\
\hline Tamil Nadu & 9 & 8.7 \\
\hline North East & 1 & 0.9 \\
\hline Kerala & 3 & 2.9 \\
\hline
\end{tabular}

Frequency of socio-demographic details. HIV: Human immunodeficiency virus

Table 2: CSF and neuroimaging findings in the study population

\begin{tabular}{lll}
\hline Investigation & Frequency & \\
\hline CSF picture & & \\
Not done & 63 & \\
TBM & 22 & \\
Cryptococcus meningitis & 6 & \\
Normal & 5 & \\
Others & 4 & Negative \\
Viral meningitis & 3 & 25 \\
\hline Other CSF investigation & Positive & 34 \\
\hline CSF India Ink & 10 & 35 \\
CSF crypto antigen & 13 & \\
CSF VDRL & 1 & \\
CSF Gram's stain & 0 & \\
CT/MRI & & \\
Not available & 63 & \\
Normal & 18 \\
Cerebral edema & 7 & \\
Cerebral atrophy & 4 & \\
Brain SOL & 4 & \\
Periventricular infarct & 4 & \\
Other infarcts & 3 & \\
& &
\end{tabular}




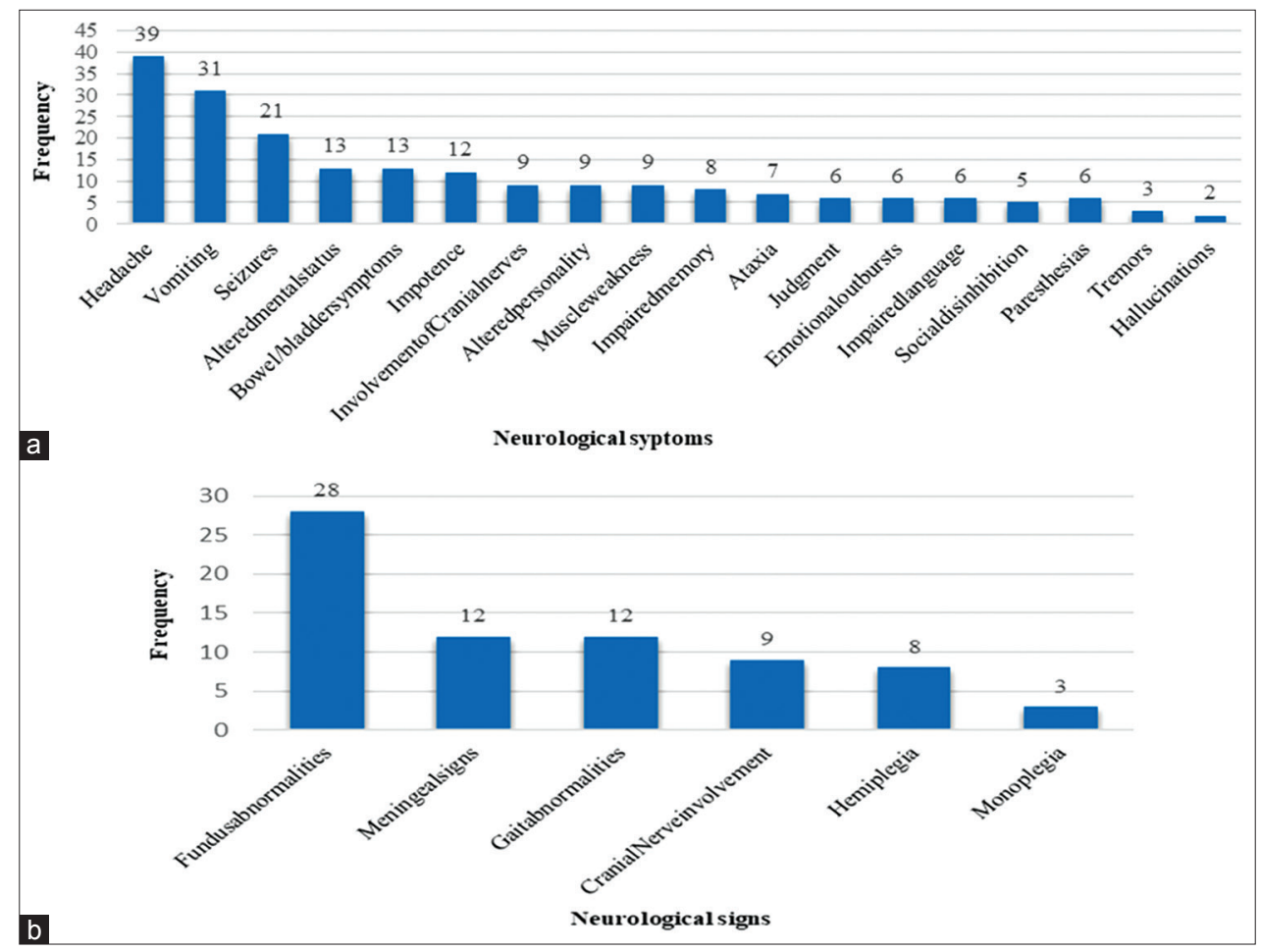

Fig. 1: (a and b) Clinical neurological manifestations in human immunodeficiency virus patients

three additional patients had coexistent tuberculous and cryptococcal meningitis. Thus, infections are the most common neurological manifestations in patients with HIV. Among the three patients with neuropathy, one patient was on Stavudine (STV) and the neuropathy was related to the drug and the other two patients probably had HIV induced neuropathy.

Association of CD4 and absolute lymphocyte count with neurological manifestation

The mean CD4 with neurological manifestations was 107.34 and without neurological manifestations was 213.93 . This was statistically significant $(\mathrm{p}=0.00)$. The mean ALC in patients with neurological manifestations was 1009.22 and in those without neurological manifestations was 1280.37 . This was not statistically significant $(p=0.06)$. Thus, CD4 counts showed a better correlation with the occurrence of neurological manifestations than ALC (Table 4).

Correlation of ART and the neurological manifestation

The duration of ART did not show a correlation with the occurrence of neurological complications (Table 5).

\section{DISCUSSION}

Neurological manifestations in HIV patients are influenced by host genetic factors, environmental factors unique to developing countries, and patient's accessibility to treatment. Hence, a comparative analysis of the neurological manifestations from different regions of the world is necessary. This study is aimed at studying the neurological manifestations in a South Indian population.

As this, an inpatient based study; patients with more advanced disease are likely to be included in the study. Due to the dynamics of the disease spread in our population as discussed below, males are more likely to be in an advanced disease state as compared to females, which reflects in the greater percentage of widowhood in females. Females have generally been diagnosed as HIV-positive during either routine Ante Natal checkups or when their husbands came with OI [7-9].
Table 3: Relation of mean CD4 count and neurological diagnosis in the study population

\begin{tabular}{lll}
\hline Neurological diagnosis & Frequency & $\mathbf{M}^{\dagger} \mathbf{C D 4}$ \\
\hline None & 63 & 216.78 \\
TBM & 19 & 134.54 \\
Crypto meningitis & 3 & 63.55 \\
Toxoplasmosis & 2 & 66.00 \\
CNS lymphoma & 2 & 133.00 \\
Distal symmetrical sensory neuropathy & 2 & 118.00 \\
AIDS dementia complex & 2 & 143.50 \\
Small vessel vasculitis & 2 & 178.00 \\
Viral meningitis & 3 & 154.00 \\
TBM+Crypto meningitis & 3 & 63.25 \\
Neurosyphilis & 2 & 91.00 \\
\hline
\end{tabular}

${ }^{\dagger}$ Results are expressed in Mean; calculation of mean CD4 is based on a neurological diagnosis.

Table 4: Association of ALC and CD4 count with neurological complications

\begin{tabular}{|c|c|c|c|}
\hline & \multicolumn{2}{|l|}{$\mathbf{s}$} & \multirow[t]{2}{*}{$\mathbf{p}^{*}$} \\
\hline & Yes $(M \pm S D)^{\circ}$ & No $(M \pm S D)^{\circ}$ & \\
\hline CD4 & $107.3 \pm 16.4$ & $213.9 \pm 16.4$ & 0.001 \\
\hline ALC & $1009.2 \pm 82.6$ & $1280 \pm 105.1$ & 0.06 \\
\hline
\end{tabular}

'Result are expressed in mean and standard deviation. ${ }^{*} \mathrm{p}<0.05$ statistically significant

Table 5: Association of ART and neurological complications

\begin{tabular}{lllll}
\hline & & \multicolumn{2}{c}{ Neurological complications } & \multirow{2}{*}{$\mathbf{p}^{*}$} \\
\cline { 3 - 4 } & & No & Yes & \\
\hline \multirow{2}{*}{ ART } & No & 35 & 24 & 0.072 \\
& Yes & 24 & 17 & \\
\hline
\end{tabular}

$* \mathrm{p}<0.05$ statistically significant 
The most common symptom in our study was a headache with vomiting. Seizures and altered sensorium were the other common symptoms. This is comparable with the study done by Wadia et al. [10], who documented neurological symptoms in $30 \%$ of their patients.

Incidence of fundus abnormalities was low in our study as compared to the other Indian studies [11]. The high incidence of fundal abnormalities, some of which are pathognomonic underscores the importance of fundus examination in these patients.

CSF examination is an invaluable investigation in HIV-positive patients with neurological symptoms as they are simple to perform in limitedresource settings whereas it is cost-effective and fairly accurate $[12,13]$. A study by Satishchandra et al. [14] revealed features of cerebral atrophy in 19\% and hydrocephalus in 10\% of cases from NIMHANS, Bengaluru, India. Hydrocephalus was not found in any of our patients. Neuroimaging is useful for the diagnosis of many problems but is crucial for ruling out space occupying lesion and hydrocephalus, where the performance of a linear optimization may be detrimental to the patient.

Out of the 100 patients, 41 had neurological complications. This is comparable with the study done by Wadia et al. [10] where neurological complications of HIV disease were seen in $20 \%$ of outpatients in HIV clinics and almost half of HIV patients being treated as inpatients. Another study by Levy et al. [15] showed that at least one-third of patients with advanced HIV infection will develop neurological complications during the course of their illness.

The CD4 count and neurological manifestation were in concordance with previous studies $[9,10]$. The neurological manifestations that were seen in patients with CD4 counts greater than $200 / \mathrm{mm}^{3}$ were viral meningitis in two patients and sensory axonal neuropathy, probably Stavudine induced in 1 patient. This is an expected finding as most OIs and most HIV elated neurological complications occur at low CD4 counts.

The mean duration of ART in patients with neurological manifestations was 9.63 months and the mean duration of ART in patients without neurological manifestation was 10.24 months (difference not significant). Most of the manifestations have occurred within the $1^{\text {st }}$ year of ART.

OIs occurring in the early part of the ART could represent an incomplete immune reconstitution or an immune reconstitution syndrome. Many of our patients probably represent the former group because the CD4 counts were below $200 / \mathrm{mm}^{3}$. The lack of correlation between the duration of ART and the occurrence of neurological manifestations is reflected in the lack of correlation between the duration of ART and the CD4 counts. One reason for this could be different baseline CD4 counts. A subset of patients could be having treatment failure.

Our study was not designed to address this issue, but it was heartening to note that those patients whose CD4 counts were above $200 / \mathrm{mm}^{3}$ were protected from most of the neurological complications.

Few limitations of the study were first, the cross-sectional design which affects the serial monitoring of patients. Second, the sample size of the study and selection bias due to a greater proportion of patients being in the World Health Organization Stages 3 and 4 is another limitation, as the study was done in a tertiary care center.

\section{CONCLUSION}

Headache was a significant predictor of the occurrence of neurological complications $(\mathrm{p}=0.01)$. CSF examination revealed a positive diagnosis in the majority of the patients who underwent the test. A neurological problem was detected in 41 out of the 103 patients studied. OI remained the most common problems detected, including TBM, Cryptococcal meningitis, a combination of both and viral meningitis. HIV-related neurological problems documented (six out of 41) included AIDS Dementia Complex, neuropathy, and CNS lymphoma.
CD4 counts were significantly lower in patients with neurological complications and most of the neurological manifestations and all the OIs were documented in patients with CD4 counts below $200 / \mathrm{mm}^{3}$. Neurological complications did not show any correlation with the patient being on ART or otherwise or with the duration of ART. The possible reasons for this include differing baseline CD4 count at the start of ART and treatment failure in a subset of patients.

\section{FUTURE SCOPE}

Evaluation of neurological manifestations in HIV-AIDS patient in WHO Stages 1 and 2 to understand the primary stage of clinical findings.

\section{FUNDING ACKNOWLEDGMENT}

This research received no external funding.

\section{CONFLICTS OF INTEREST}

No conflicts of interest to disclose.

\section{AUTHORS' CONTRIBUTIONS}

Dr. Arun Singh Tejavath and Dr. Amit Mathur conceptualized and gathered the data in regard to this work. Dr. Pratima Singh, Dr. Supriya Suman, and Dr. Preeti Raj analyzed these data and necessary inputs were given toward the designing of the manuscript. All authors discussed the methodology and results and contributed to the final manuscript. Dr. Arun Singh Tejavathand and Dr. T.Murali Venkateswara Raosupervised the whole work until the completion of the whole manuscript.

\section{ETHICAL POLICY AND INSTITUTIONAL REVIEW BOARD STATEMENT}

The study was approved by the institutional ethics committee of NRI Medical College and General Hospital, Chinakakani, Guntur, Andhra Pradesh.

\section{ACKNOWLEDGMENT}

The authors are thankful to all the participants involved in this study. We are also wholeheartedly thankful to the medical superintendent of NRI Medical College and General Hospital, Chinakakani, Guntur, Andhra Pradesh, for supporting this study.

\section{REFERENCES}

1. Simoes E, Babu P, John T, Nirmala S, Solomon S, Lakshminarayana C, et al. Evidence for HTLV-III infection in prostitutes in Tamil Nadu (India). Indian J Med Res 1987;85:335-8.

2. Sandeep B, Chavan VR, Raghunathan M, Arshad M, Sayana SB. Factors influencing the substitution of art in HIV/aids patients on first line highly active antiretroviral therapy. Asian J Pharm Clin Res 2014;7:117-20.

3. Aher A. HIV and AIDS in India. Brighton, United Kingdom: Avert; 2020.

4. Patrick M, Johnston J, Power C. Lentiviral neuropathogenesis: Comparative neuroinvasion, neurotropism, neurovirulence, and host neurosusceptibility. J Virol 2002;76:7923-31.

5. Bensalem M, Berger J. HIV and the central nervous system. Compr Ther 2002;28:23-33.

6. Deshpande A, Patnaik M. Nonopportunistic neurologic manifestations of the human immunodeficiency virus: An Indian study. J Int AIDS Soc 2005;7:2.

7. De S, Marsh J. HIV-1 Nef inhibits a common activation pathway in NIH-3T3 cells. J Biol Chem 1994;269:6656-60.

8. Lanjewar D, Jain P, Shetty C. Profile of central nervous system pathology in patients with AIDS: An autopsy study from India. AIDS 1998;12:309-13.

9. Suryana K, Suharsono H, Budiasa G, Antara J, Astuti P, Indah I, et al. Correlations between cluster differentiations 4 counts, human immunodeficiency virus clinical stages, and haemoglobin level among human immunodeficiency virus patient patients with anemia in Merpati clinic, Wangaya hospital, Denpasar, Bali Indonesia: A cross-sectional. Asian J Pharm Clin Res 2019;12:426-9. 
10. Wadia RS, Pujari SN, Kothari S, Udhar M, Kulkarni S, Bhagat S, et al. Neurological manifestations of HIV disease. J Assoc Physicians India 2001;49:343-8.

11. Kumar P, Sharma N, Sharma NC, Patnaik S. Clinical profile of tuberculosis in patients with HIV Infection/AIDS. Indian J Chest Dis Allied Sci 2002;44:159-63.

12. Saag M, Graybill R, Larsen R, Pappas P, Perfect J, Powderly W, et al. Practice guidelines for the management of cryptococcal disease. Clin Infect Dis 2000;30:710-8.

13. Graybill J, Sobel J, Saag M, van der Horst C, Powderly W, Cloud G, et al. Diagnosis and management of increased intracranial pressure in patients with aids and cryptococcal meningitis. The NIAID mycoses study group and AIDS cooperative treatment groups. Clin Infect Dis 2000;30:47-54

14. Satishchandra P, Nalini A, Gourie-Devi M, Khanna N, Santosh V, Ravi V, et al. Profile of neurologic disorders associated with HIV/AIDS from Bangalore, South India (1989-96). Indian J Med Res 2000;111:14-23.

15. Levy R, Bredesen D, Rosenblum M. Neurological manifestations of the acquired immunodeficiency syndrome (AIDS): Experience at UCSF and review of the literature. J Neurosurg 2007;107:1253-73. 